\title{
College Women's Perception and Knowledge of Human Papillomavirus (HPV) and Cervical Cancer
}

\author{
Ricardo Lopez and Shari McMahan \\ California State University, Fullerton
}

\begin{abstract}
Human papillomavirus (HPV) infections are one of the most common types of sexually transmitted infections in the United States. The highest rates of HPV infection are found in adult's ages 18-28 years. This study utilizes the Health Belief Model to assess knowledge and perception of HPV infection and cervical cancer in college-age women and their intent to reduce their numbers of sex partners and request that their partner wear a condom during their next sexual encounter to prevent HPV infection. Even though most college women have heard of HPV, it appears that $79.5 \%$ of women in this study rated their subjective knowledge of HPV as poor, and only $58 \%$ knew that a vaccine now exists to prevent HPV infection. HPV health promotion campaigns should do more to incorporate HPV vaccine education in STD and HPV educational interventions.
\end{abstract}

(C) 2007 Californian Journal of Health Promotion. All rights reserved.

Keywords: Human Papilloma Virus, Sexually Transmitted Disease, Cancer, Women

\section{Introduction}

Human Papillomavirus (HPV) infections are one of the most common types of sexually transmitted infections in the United States (Koutsky, 1997). Of the 100 types of HPV strains currently discovered 18 are considered high risk, oncogenic HPVs (Schiffman, 2003). Infection with oncogenic HPV strains is a central causal factor in cervical cancer since virtually all cervical cancer cells in $90 \%$ of cervical cancer cases contain these types of HPVs (Bosh and de Sanjose, 2003). In 2003, approximately 12,200 new cases of cervical cancer with 4,100 deaths due to this disease were expected to have occurred (Franco, Schlecht, and Saslow, 2003).

The highest rates of HPV infection are found in adults ages 18-28 years (Koutsky, 1997). Research demonstrates that $10 \%$ to $39 \%$ of sexually active young women, especially those of college age (18-24), are infected with high risk HPV at any point in time. Winer et al. (2002) studied incidence data and risk factors for transmission among 603 female University of Washington students (18-20 years of age). These 603 women were followed between 1990 and
2000 and contacted at four-month intervals over a period of ten years. At each interval, a sexual and health questionnaire was completed and vulvogenital and cervical samples were collected to test for HPV presence. They found that at 24 months, the cumulative incidence of first time infection was $32.3 \%$. Cumulative incidence of high-risk HPV types in this population was a high as $10 \%$ (Winer et al., 2002). A study conducted by Auvinen et al. (2005) analyzed the prevalence of HPV in college aged women by studying two different groups of college women. Group 1 attended the doctor for general health examinations and group 2 went to a general practitioner seeking contraception. Vaginal selfsamples were collected from 919 participants in group 1 (mean age of 22.7) and cervicovaginal swabs were collected 550 participants (mean age 24.8) in group 2. Of the 1469 samples, 485 (33\%) were HPV DNA positive. In all 409 positive samples, $84.3 \%$ were positive for highrisk HPV DNA and 147 samples (10\%) were positive for both low risk and risk HPV DNA (Auvinen et al., 2005). Shin et al. (2004) examined the incidence of HPV in both female (median age 19) and male (median age 22) college students. Self-collection of vaginal cells 
were collected from female students and evaluated for the prevalence of 25 HPV strains in 672 female participants. Twenty-two different types of HPV DNA were detected in $15.2 \%$ of the female participants with high-risk HPV types predominantly present. The prevalence of HPV among sexually active women was thirty-nine percent (39\%) (Shin et al., 2004). The aforementioned studies on college female students showed that HPV is present at substantial rates.

HPV infection is a highly preventable disease, but precaution depends, in part, on the cognitive aspects of young women (Ingledue, Cottrell and Bernard, 2004; Lambert, 2001; Vail-Smith and White, 1992). Unfortunately, young women lack sufficient knowledge, have misperceptions about their susceptibility to HPV, and are unaware of the risk factors that increase the likelihood of HPV infection (Ingledue et al., 2004; Lambert, 2001; Vail-Smith and White, 1992). Vail-Smith and White (1992) studied these issues by developing an instrument that measured demographic behaviors, HPV risk and prevention behaviors, and awareness of HPV. They surveyed a sample of 263 sexually active college women of which $90 \%$ were white, $9 \%$ black and $2 \%$ classified as other. They concluded that respondents lacked awareness of HPV (a total of $87 \%$ of participants had either never heard of HPV or were not sure whether they had heard of it). Women in this study were at considerable risk for contracting HPV if they engaged or had one or more of the following: intercourse at early age, history of STDs, multiple sex partners or smoked. Vail-Smith and White were also able to find that study participants were not practicing preventative behaviors that could reduce their risk of HPV and its serious consequences: $26 \%$ engaged in sexual intercourse without using a condom as a means of protection to HPV, 31\% had never had a Pap smear and only 32\% knew that a woman under the age of 18 should have her first Pap test soon after having sexual intercourse for the first time.

In another study, Lambert (2001) explored college woman's knowledge of HPV through a questionnaire that elicited their knowledge of
HPV, including complications and prevalence values. The women went through a brief HPVfocused educational intervention. Three months later the cohorts were then reevaluated with the same questionnaires. Forty women participated in this study. Researchers found that preintervention women answered $45 \%$ of the HPV questions correctly compared with $75 \%$ of the non-HPV items. After the intervention, $78 \%$ of the HPV questions were answered correctly among women and $61 \%$ of the non-HPV items were answered correctly. There was significant statistical improvement in scores for all HPVrelated questions in women. Researchers were able to show that despite the high prevalence and serious complications associated with HPV infection most college students knew very little about HPV before the educational intervention (Lambert, 2001).

Ingledue et al. (2004) examined HPV/cervical cancer knowledge, perceptions and sexual behaviors among 428 college women (ages 1830) using selected constructs of the Health Belief Model. Results indicated that low perceived susceptibility was coupled with highrisk sexual behavior among the woman in this study. The aforementioned studies show that college age women lack sufficient knowledge of HPV, have misperceptions of HPV and ICC, are unaware of the risk factors of contracting HPV, and may not practice the safest sexual behaviors to prevent HPV infection. This may indicate a rising wave of cervical cancer in the future, since HPV infection is a risk factor for cervical cancer.

Previous studies on HPV and college women have focused on knowledge, perceptions and attitudes but little attention has been focused on examining intent to perform HPV preventative sexual behaviors. The purpose of this study is to utilize the Health Belief Model to assess knowledge and perception of HPV infection and cervical cancer of college-age women (ages 1825), their intent to reduce their numbers of sex partners and intent to request that their partner wear condoms during their next sexual encounter to prevent HPV infection. 


\section{Methods}

\section{Participants}

Participants in this study were college-age women (18-25) attending Health Science (HESC101) Personal Health classes at a large University (>30,000 students) in the Southern California region. HESC101 is a general education course that is available to all students from a wide range of academic departments. Class sizes range from 25-125 students with mixed representation of ethnicities, majors, and class levels. Approximately 10 sections of HESC101 are offered each semester. About 70\% of the students that enroll in HESC101 are women. All women (aged 18 and over) were eligible to participate in this study. This study was in compliance with the Institutional Review Board (human subjects) at the University. Oral consent was obtained on all eligible participants. In 2006, the ethnic distribution of the University was: 1\% American Indian, 22\% Asian/Pacific Islander, 3\% Black, 25\% Hispanic, 35\% White, $11 \%$ unknown, and 4\% International Students.

\section{Theoretical Framework}

The Health Belief Model (HBM), a value expectancy model, was used to describe the participant's perceptions about HPV and cervical cancer and to predict preventative sexual health behaviors (Igledue et al., 2004). The HBM model has been utilized in other STI studies to predict preventative behavior towards $\mathrm{HIV}$, and to assess perception towards that infection. The HBM contends that preventative action and perception of particular disease is influenced by an individual's perceived susceptibility to the disease, perceived severity to the disease (perceived susceptibility and severity are together called perceived threat), perceived benefits of reducing risk to the disease, and perceived barriers to taking preventative action (Glanz, Lewis and Rimer, 2002). A construct that today is considered part of the HBM, but was not an original construct of the HBM, is self efficacy. Self-efficacy is defined as one's self-judgments of personal capabilities to initiate and successfully perform specified tasks at designated levels, expend greater effort, and persevere in the face of adversity (Bandura, 1986). The original focus of the model was on simple behaviors and not on lifestyle behaviors that required long term changes. Evidence shows that self-efficacy plays a central role in the prediction of initiation and maintenance of healthy behavioral change (Glanz et al., 2002).

\section{Instrument}

Female participants took a modified version of the self-administered questionnaire called the Knowledge and Perceptions Survey (KAPS) to measure the stated variables of this study. The KAPS instrument was created by McPartland et al. (2005) to assess perceived severity, susceptibility, knowledge of HPV, and intent to change behavior. The knowledge scale had an established internal consistency (Crohnbach's alpha $=0.93$ ) in a study conducted by Yacobi et al. (1999). This study used the same knowledge scale and incorporated it within a modified KAPS questionnaire. Face validity of the questionnaire was assessed by four health science faculty and two health professionals from the Division of Cancer Control and Prevention Research at the University of California at Los Angeles. The initial goal was to design a modified questionnaire of 35 questions that would take participants less than 15 minutes to complete. After assessment, a total of 36 questions were included in the questionnaire and it took participants an average of seven minutes to complete.

Participants were asked questions through the HBM framework to assess their intent to wear condoms the next time they have sex and to reduce their number of future sexual partners to prevent HPV infection. General knowledge of HPV and cervical cancer was assessed via 13 T/F HPV questions (Table 1). Question 10 from the knowledge scale was modified from "there is a vaccine being developed to prevent HPV infection" to "a vaccine exists to prevent HPV infection" due to the advent of a vaccine that prevents HPV infection. Questions for perceived benefits and barriers were created for this study. The questions assessing self-efficacy were adapted from Wulfert and Wan (1993) and their study of self-efficacy to wear condoms to prevent HIV in a population of college-age students. 
Table 1

Thirteen True/False Questions to Assess General Knowledge of HPV and Cervical Cancer in CollegeAge Women (Source: McPartland et al., 2005)

\begin{tabular}{|l|l|}
\hline \multicolumn{1}{|c|}{ No. } & \\
\hline 1. & HPV can cause genital warts \\
\hline 2. & HPV can cause cervical cancer \\
\hline 3. & Most people with genital HPV have no visible signs or symptoms. \\
\hline 4. & If a woman's Pap smear is normal., she does not have HPV \\
\hline 5. & Changes in a Pap smear may indicate that a woman has HPV \\
\hline 6. & Genital warts are caused by the herpes virus \\
\hline 7. & Pap smears will almost always detect HPV \\
\hline 8. & HPV can be passed from the mother to her baby during birth \\
\hline 9. & A negative test for HPV means that you do not have HPV \\
\hline 10. & A vaccine exists to prevent HPV infection (question modified due to the advent of Gardasil). \\
\hline 11. & Having one type of HPV means that you cannot acquire new types \\
\hline 12. & I can transmit HPV to my partner(s) even if I have no HPV symptoms \\
\hline 13. & HPV can cause Herpes \\
\hline
\end{tabular}

The questionnaire also included questions to obtain pertinent demographic information such as: age, ethnic background, full time/part time student status, college level, type of relationship (monogamous), number of sexual partners within the last 12 months, and whether the participants lived at home or independently. Participants were also asked directly if they were sexually active. Furthermore, they were also asked if they used a condom during their last sexual encounter and how often they used condoms with their current sexual partner(s). These aforementioned questions were included in the modified KAPS questionnaire to obtain a better dimension of the participant's use of condoms and to give a clearer picture of their intent to have their partner wear condoms in the future.

\section{Procedures}

There were a total of 10 personal health classes (with seven different instructors) offered during the Spring Semester 2007. Ten sections of the personal health course were given "live" at the campus and two were offered as "on-line" web based courses. A letter and e-mail were sent to personal health instructors requesting class time to distribute the questionnaires during the last ten minutes of a pre-determined class lecture.
No outreach was given to internet based classes because the collection of completed questionnaires from such participants would have compromised the anonymity of potential participants.

Permission was granted from the six of the seven professors to pass out the questionnaires in their classes. Questionnaires were collected from a total of nine personal health classes (one professor taught three classes, another one taught two classes). The questionnaires were passed out before the topic of sexually transmitted infections was presented in each class. All students in attendance were given the self-administered questionnaire to create an atmosphere of inclusion. This study does not include questionnaires filled out by male participants.

In each class the investigator first verbally notified the student of their rights as participants as stated by IRB protocol. The study investigator then described the necessary steps required to filling out the questionnaire without giving too much information regarding specifics of the study. After completing the survey, students were asked to place all completed, partially completed and incomplete questionnaires in a 
box located in the front of the room. This enabled the opportunity to ascertain the number of non-respondents. The study investigator left the room while the participants filled out their questionnaires. The box and the absence of the study investigator were actions that intended to increase the anonymity and comfortability of potential participants. All personal health professors were offered an HPV guest lecture in appreciation for allocating class time to aid this study. General knowledge HPV pamphlets (published by the Centers for Disease Control) were placed next to the questionnaire box for students to take at will.

\section{Design and Analysis}

The operationalization of the HBM was expected to provide a more holistic look at cognitive measures that affect women's behavior in regards to HPV and cervical cancer. However, the HBM was not operationalized as one unit since research suggests that it is not effective at measuring perceptions and behavioral intent when tested as a collection of equally weighted variables operating simultaneously (Glanz et al., 2002). Each variable is independent of each other and some have been shown to be more predictive of behavior than others depending on the priority population and the behavioral intent being measured. Each HBM variable was operationalized (via a 4-point Likert scale) and assessed as predictor variables (Table 2). Two variables, intent to reduce number of sexual partners and intent of using a condom the next time were utilized as dependent (outcome) variables. This study measured intent to carry out two different HPV preventative sexual behaviors. Demographic variables were also analyzed for possible confounding affects including: participant's ethnic background, number of sexual partners in the last 12 months, whether the participants were in a relationship and if they lived independently or dependent on a parent/guardian.

Table 2

Operationalization of HBM to Assess Perceptions of HPV in College-Age Women

\begin{tabular}{|l|l|l|}
\hline \multicolumn{1}{|c|}{ Predictor Variables } & \multicolumn{1}{|c|}{ Construct } & \multicolumn{1}{|c|}{ Source } \\
\hline Perceived Susceptibility & $\begin{array}{l}\text { 1. How likely do you think it is that you will get } \\
\text { infected with HPV? }\end{array}$ & $\begin{array}{l}\text { McPartland et al. } \\
\text { (2005) }\end{array}$ \\
\hline Perceived Severity & $\begin{array}{l}\text { 2. How severe do you think it would be to have Human } \\
\text { Papillomavirus (HPV) infection? }\end{array}$ & $\begin{array}{l}\text { McPartland et al. } \\
\text { (2005) }\end{array}$ \\
\cline { 2 - 3 } Perceived Benefits & $\begin{array}{l}\text { 3. How likely do you think that minimizing your } \\
\text { number of partner(s) will help you reduce your } \\
\text { chances of contracting HPV? }\end{array}$ & $\begin{array}{l}\text { Created for this } \\
\text { Study }\end{array}$ \\
\hline Perceived Barriers & $\begin{array}{l}\text { 4. How difficult would it be to reduce your number of } \\
\text { sexual partner(s) for the sake of preventing HPV } \\
\text { infection? }\end{array}$ & $\begin{array}{l}\text { Created for this } \\
\text { Study }\end{array}$ \\
\hline Self-Efficacy & $\begin{array}{l}\text { 5. How confident are you in your ability to use a } \\
\text { condom for protection the next time you have sex to } \\
\text { prevent HPV infection? }\end{array}$ & $\begin{array}{l}\text { Wulfert and Wan } \\
\text { (1993) }\end{array}$ \\
\hline
\end{tabular}

Outcome and predictor variables were also examined via a 4 point Likert-type scale and dichotomized as in McPartland et al. (2005) for the purpose of data analysis. Unadjusted logistic regression analysis was performed to assess the relationship between all the variables aforementioned. Predictor variables with a p- value less than 0.20 were then included in an adjusted multivariate logistic regression model. This was performed to calculate the odds ratio (OR) with constructs significant at the univariate level, with all other variables equal. Furthermore, in a separate analysis the Health Belief Model and ethnicity were also examined 
via an adjusted logistic regression model in order to test the predictability of $\mathrm{HBM}$ as a model (not a combination of constructs).

It was anticipated that participants will have low levels of all predictor variables (as cited in Table 2). The HBM was not expected to be a good predictor of the participant's intent to change future sexual behavior. Participants with lower scores on independent variables were predicted to have lower intention to reduce number of sexual partners. Also, participants with lower scores on independent variables were predicted to have lower intention to use condoms the next time they have sex. Participants that were in a monogamous relationship were not expected to be more likely to intend to wear condoms the next time they have sex and to reduce their number of sexual partners in the future to prevent HPV infection. Ethnicity and living independently were expected to be confounding variables. Furthermore, those that have never heard of HPV before and those that have low subjective knowledge of HPV were not expected to intend to change their future sexual behavior. All appropriate statistical analyses were conducted with the Statistical Package for the Social Science (SPSS) software, version 14.0 (SPSS Inc., Chicago, IL).

\section{Results}

Of the 190 females in the HESC101 classes, a total of 186 questionnaires were collected. Four students were under the age of 18 . Of the 186 collected, 172 were included in data analysis (participation rate 93\%). Fourteen surveys were excluded because the survey was less than $50 \%$ complete. Of the 172 participants $50.6 \%$ were freshmen, 35.5\% were sophomores, 9.9\% were juniors, and 4.1 were seniors. Ninety-seven percent (97\%) were full time and 2.9\% were part time students. The ethnic distribution of the participants included $4.1 \%$ Black/African Americans, 13.4\% Asian/Pacific Islander, 42.4\% Latino/Hispanics 30.2\% White and 7.6\% other. This was similar to the ethnic distribution of the University. Seventy-six percent of the participants live independently without the presence of parent/guardians.
Of the 172 women, $61.6 \%$ stated that they were in a relationship with a significant other and $38.4 \%$ stated they were not. In the 105 participants that responded, 96.2\% considered themselves to be in monogamous relationships. Over $60 \%(n=105)$ of the participants were sexually active at the time the questionnaire was administered. A total of 106 women stated that they were sexually active with men only. The rest either answered no or chose the option marked "not sexually active." Thirty-three percent (33.1\%) of the participants have not had a sexual encounter in the last 12 months, $49.4 \%$ had one sexual partner, $14.5 \%$ had two to three partners, $2.3 \%$ had $4-5$ partners and .6\% (1 participant) had more than 5 sexual partners. One-hundred eleven participants responded to the question that asked whether or not they asked they partner to wear a condom during their last sexual encounter (the rest marked that they were not sexually active): $49.5 \%$ did not use a condom and $50.5 \%$ did request the use of a condom. One hundred six participants answered the questions that asked about their condom wearing behavior and $47.2 \%$ tended not to use a condom and $52.8 \%$ used a condom during their sexual encounters.

Of the 172 participants, $21.5 \%$ had never heard of HPV. Seventy-eight percent (78.5\%) had heard about HPV through various sources (each category is non-inclusive): $55.8 \%$ had heard about it through television/radio, 37.2\% had heard about it through classes at the University, 29.1\% percent had heard about through a family member, $20.9 \%$ had heard about it through a health care provider, $17.4 \%$ had heard about through newspapers/magazines, and 16.3\% heard about it through the internet. Only five participants (2.9\%) had heard about HPV from a significant other/male partner.

Of the 172 female participants, $79.5 \%$ felt that they had poor subjective knowledge of HPV and $20.5 \%$ rated their subjective knowledge as "good." Most notably, 55\% (n=160) knew that HPV causes genital warts, 91.4\% $(n=162)$ knew that HPV can cause cervical cancer, 58\% $(n=157)$ knew that there now exists a vaccine to prevent certain types of HPV infection, and 92.4\% ( $\mathrm{n}=158)$ knew that that they could still 
transmit HPV to their partners even if they do not have any symptoms (Table 3). Approximately $68.2 \% \quad(n=148)$ of the participants scored above the 50th percentile and $31.8 \%$ scored below the 50th percentile and overall participants had a mean score of $63.69 \%$.

Table 3

College-Age Women's Knowledge of HPV and Cervical Cancer

\begin{tabular}{|ll|c|c|}
\hline \multicolumn{1}{|c|}{ Variable } & Answer & $\begin{array}{c}\text { Answered } \\
\text { Correctly (\%) }\end{array}$ \\
\hline 1. & HPV can cause Herpes & False & 43.1 \\
\hline 2. & Genital warts are caused by HPV & True & 55.0 \\
\hline 3. & HPV can cause cervical cancer & True & 91.4 \\
\hline 4. & If a woman's Pap smear is normal, she does not have HPV & False & 65.6 \\
\hline 5. & Changes in a Pap smear may indicate that a woman has HPV & True & 78.8 \\
\hline 6. $\quad$ Genital warts are caused by the herpes virus & False & 22.5 \\
\hline 7. & Pap smears will almost always detect HPV & False & 55.6 \\
\hline 8. $\quad$ HPV can be passed from the mother to her baby during birth & True & 54.8 \\
\hline 9. & A negative test for HPV means that you do not have HPV & False & 38.4 \\
\hline 10. A vaccine exists to prevent HPV infection (question modified due to the & True & 58.0 \\
\hline 11. Most people with genital HPV have no visible signs or symptoms. & True & 84.4 \\
\hline 12. Having one type of HPV means that you cannot acquire new types & False & 87.9 \\
\hline 13. I can transmit HPV to my partner(s) even if I have no HPV symptoms & True & 92.4 \\
\hline
\end{tabular}

A majority of participants (83.1\%) perceived that contracting HPV infection would be severe. Of the167 participants that answered the question about perceived susceptibility to HPV infection, $84.4 \%$ did not feel susceptible to HPV infection (Appendix A). In addition, 41.2\% intended to use condoms the next time they have sex and $57 \%$ intend to reduce their number of sex partners to decrease their probability of contracting HPV infection.

Each construct of the HBM was independently regressed with each of the two outcome variables of the study (Appendix B). Participants with greater self-efficacy were more likely to request that their partners wear condoms [OR=14.59, CI (5.44-39.14)] during their next sexual encounter to prevent HPV infection. As seen in Appendix B, participants that were in relationships at the time of the study were more likely to intend to request that their partners wear condoms [OR=3.36, CI (1.16-9.70)] and reduce their number of sexual partners to prevent HPV infection [OR=.23, CI (.07-.68)].
Ethnicity and student living situation was not a predictor of HPV preventative sexual behavior. With all constructs of the HBM and ethnicity equal, participant's self-efficacy to request proper condom use and perceived severity to HPV infection were protective factors in those that intend to wear condoms to prevent HPV infection (Table 4). In addition, being of Asian/Pacific Islander and White/Non-Hispanic decent were also seen as protective factors in those that intended to wear condoms to prevent HPV infection.

\section{Discussion}

Most studies that have analyzed college-age women's perceptions, attitudes and knowledge of HPV have been done with primarily White/non-Hispanic participants (Burk et al., 1996, Phillips et al., 2003; Ramirez et al., 1997; Yacobi et al., 1999). This study was representative of a multi-ethnic population typical of the ethnic representation at this University. 
Table 4

Adjusted Odd Ratios for the Health Belief Model and Ethnicity with Intent to Reduce Number of Sex Partners and Intent to Wear Condoms

\begin{tabular}{|c|c|c|c|c|c|c|}
\hline \multirow[t]{2}{*}{ HBM Constructs } & \multicolumn{3}{|c|}{$\begin{array}{c}\text { Intent of Wearing Condoms } \\
\text { During the Next Sexual } \\
\text { Encounter to Prevent HPV } \\
\text { Infection } \\
\end{array}$} & \multicolumn{3}{|c|}{$\begin{array}{c}\text { Intent of Reducing the Number of } \\
\text { Future Sex Partners to Prevent } \\
\text { HPV Infection }\end{array}$} \\
\hline & $\mathbf{N}$ & OR & $(95 \% \mathrm{CI})$ & $\mathbf{N}$ & OR & (95\% CI) \\
\hline \multicolumn{7}{|l|}{ Perceived Benefits } \\
\hline Yes & 90 & 1.86 & $(0.51-6.71)$ & 90 & 2.10 & $(0.52-8.40)$ \\
\hline No (Not Likely) & 21 & 1.00 & & 20 & 1.00 & \\
\hline \multicolumn{7}{|l|}{ Perceived Susceptibility } \\
\hline Yes & 19 & 1.59 & $(0.42-6.07)$ & 19 & 1.40 & $(0.27-7.23)$ \\
\hline No & 92 & 1.00 & & 91 & 1.00 & \\
\hline \multicolumn{7}{|l|}{ Self-Efficacy } \\
\hline Yes & 35 & $0.02 *$ & $(0.00-0.09)$ & 35 & 0.31 & $(0.09-1.04)$ \\
\hline No & 76 & 1.00 & & 75 & 1.00 & \\
\hline \multicolumn{7}{|l|}{ Perceived Severity } \\
\hline Yes & 92 & $0.07^{*}$ & $(0.01-0.47)$ & 91 & 0.97 & $(0.22-4.31)$ \\
\hline No & 19 & 1.00 & & 19 & 1.00 & \\
\hline \multicolumn{7}{|l|}{ Perceived Obstacles } \\
\hline Yes & 107 & 0.15 & $(0.01-2.52)$ & 106 & 0.98 & $(0.08-12.68)$ \\
\hline No & 4 & 1.00 & & 4 & 1.00 & \\
\hline \multicolumn{7}{|l|}{ Ethnicity } \\
\hline Latino & 44 & 0.27 & $(0.03-2.40)$ & 43 & 0.53 & $(0.05-5.14)$ \\
\hline Other Ethnicities & 67 & 1.00 & & 67 & 1.00 & \\
\hline White & 40 & $0.10 *$ & $(0.01-0.97)$ & 40 & 0.33 & $(0.03-3.41)$ \\
\hline Other Ethnicities & 71 & 1.00 & & 70 & 1.00 & \\
\hline Asian & 13 & $0.07 *$ & $(0.01-0.88)$ & 13 & 0.27 & $(0.02-4.00)$ \\
\hline Other Ethnicities & 98 & 1.00 & & 97 & 1.00 & \\
\hline
\end{tabular}

* Significant at the $\mathrm{p}<0.05$ level

About $21.5 \%$ of the participants in this study had never heard of HPV prior to this study. Philips et al. (2003) and Yacobi et al. (1999) reported that $69.4 \%$ and $63 \%$ of their participants had never heard of HPV, respectively. Approximately $68.2 \%(n=148)$ of the participants scored above the 50 th percentile and $31.8 \%$ scored below the 50th percentile. However, the mean knowledge score was $63.69 \%$ which suggests similar knowledge deficits reported among college-age women (Ramirez et al., 1997; Vail-Smith and White, 1992; Yacobi et al., 1999). Pitts and Clarke (2002) reported an overall low awareness of risk factors for cervical cancer, amongst those knowledgeable of HPV infection. These results suggest that despite the advent of vaccines to prevent HPV and the impact of cervical cancer deaths there has not been major advances in
HPV awareness and education in women at the college level. This may be because HIV health education overshadows other STI education efforts including that of HPV (Yacobi et al., 1999). Comparatively, a larger percentage of women in this study have heard of HPV. Women reported hearing of HPV through a myriad of sources but overwhelmingly through TV and radio, newspapers, magazines and the internet. This is likely due to the strong media campaigns strongly advocating for the widespread availability of the newly developed drug named Gardasil (vaccine that prevents most types of HPV infection in women). Only 20.9\% had heard about it through a health care provider and 5 participants (2.9\%) had heard about HPV from a significant other/male partner. Outreaching to medical doctors should be a top 
priority and more emphasis should be place on training them to be key roles players in the informed decisions making process of collegewomen and preventative behaviors that decrease the likelihood of HPV infection. Having heard of HPV, however, also does not translate into higher perceived knowledge of HPV. In fact, $79.5 \%$ of women in this study rated their subjective knowledge of HPV as poor, and only $58 \%$ knew that a vaccine now exists to prevent HPV infection. HPV health promotion campaigns should do more to incorporate HPV vaccine education in STD and HPV educational interventions.

College-age women in this study did have high knowledge of important concepts of HPV infection and cervical cancer. Women scored over $80 \%$ on questions that had to do with transmission, infection and links to cervical cancer (items \#3, \#11, \#12, and \#13 on the knowledge scale). However, college-age women need more information regarding the symptoms and behavior of HPV infection since more than $43 \%$ thought that HPV causes herpes and 22\% thought that genital warts are caused by the herpes virus. Also, it is imperative to teach women about the efficacy and availability of diagnostics tests to detect HPV infection since $38 \%$ believed that a negative test for HPV means that they do not have HPV.

The majority of participants (83.1\%) perceived HPV infection to be severe. In Yacobi et al. (1999) and Ingledue et al. (2004) participants felt low perceived susceptibility to HPV infection. Similarly, in this study only $15.6 \%$ of the participants felt susceptible to HPV infection. However, a large majority of participants did not perceive obstacles and had high perceived benefits in reducing their number of sex partners for the sake of preventing HPV. Appropriate on campus health education efforts should create or modify interventions to place emphasis on effective ways to reduce the number of future sexual partners. Research shows that sex abstinence education is not effective in reducing the likelihood of a college students having sex so health educators will have to come up with other innovative ways to promote the reduction of sex partners. Only 20\% of the participants felt self-efficacious to put a condom on their male partner(s). Despite of the existence of female condoms, male condoms are the standard use of protection among sexually active couples thus it is advantageous that women also know how to put on a condom on their male partners to help prevent HPV infection.

Condoms are a primary method of preventing STIs in sexually active individuals yet less than half of all college students report using condoms consistently (Zak-Place and Stern, 2004). Consistent with these results $49.5 \%$ did not use a condom and $50.5 \%$ did request the use of a condom form their male partners. Of 106 participants that answered the questions about condom wearing behavior $47.2 \%$ tend not to use condom and $52.8 \%$ tend to use a condom during their sexual encounters. Previous condom wearing behavior of women is indicative of their intent to wear condoms the next time they have sex; $41.2 \%$ intent to wear condoms the next time they have sex. Condom wearing behavior is important since only $57 \%$ of women intent to reduce their number of future sex partners to prevent HPV infection. More sexual encounters increase the likelihood of infection especially if the majority women do not intent to request their male partners to wear condoms to protect themselves. Thus, it is important for health promotion campaigns to be able to predict college age women's intent to reduce future sex partners and their self-efficacy to put on a condom on their male partner(s) during the next sexual encounter in order to prevent HPV infection.

In this study, self-efficacy was found to be a predictive factor of intent to wear condoms with their male partner(s) during their next sexual encounter at both the univariate and multivariate level. Thus if women felt confident in putting on a condom on their male partner(s) they are more likely to intent to make their partners wear a condom for the sake of preventing HPV infection during their next sexual encounter. The multivariate model incorporated key constructs of the HBM (perceived severity, susceptibility, benefits, obstacles and self-efficacy participant ethnicity) that were regressed with women's 
intent to request that their male partner's wear condoms. Overall, these results show that perceptions of disease may not be as important as having the confidence (self-efficacy) of wearing condoms during sexual encounters. Similar to Zak-Place and White (2004), selfefficacy was found to be a significant predictor of intent to use condoms at the multivariate level yet within the context of HPV health threats (50\% of participants in this study were female). Winer et al. (2006) found that women are less likely to contract HPV infection if their male partners wear a condom. Wearing condoms is primarily a male oriented decision thus increasing the self efficacy of women to put condoms on their male partner(s) could increase a women's role in that decision and help reduce the infection rate of HPV in that community.

Previous studies have examined the perceptions and knowledge of sexually experienced compared to sexually inexperienced female participants (Ramirez et al., 1997) and others have looked women from a large range of ages (Pitts and Clarke, 2002) but none has examined the presence of a relationship with a significant other as a predictor of HPV preventative sexual behavior specifically in college-age women. Participants in this study were more likely to intend to wear a condom and reduce their number of future male partners, in order to prevent HPV infection, if they were in a relationship with a significant other. In addition, women with high perceived severity to HPV infection were more likely to request that their male partner(s) wear a condom during their next sexual encounter. Ingledue et al. (2004) found no relationship between perceived severity in relation to condom use. Lastly, women from the white/non-Hispanic and Asian/Pacific-Islander community were more likely to intend to request their male partner(s) wear condoms during their next sexual encounter. As mentioned earlier very few studies have examined women's perception, knowledge and intent to perform HPV preventative sexual behavior in college-age women.

The utility of the HBM as a full comprehensive model has never been examined with in the context of college-age men and HPV and cervical cancer. Previous studies have tested the HBM within the context of STIs to identify its predictive power of preventative sexual behavior in a college-age population (Petosa and Jackson, 1991; Zak-Place and Stern, 2004). Most recently Zak-Place and Stern (2004) did not find evidence to demonstrate the use of HBM in predicting college-age students' sexual preventative behavior. The results of this study support the same conclusions in Zak-Place and Stern with the exception of two variables from the HBM; self-efficacy and perceived severity.

The results of this study also show that while perceptions are important the most significant predictive factor in the HBM to intent to wear condoms with future sex partners is selfefficacy. The original intent of the HBM was to predict simple behavior and not lifestyle behaviors that require long-term changes (Glanz et al., 2002). Intent to wear condoms is a longterm behavior change and is something that sexually active college-age women must reevaluate every time before a sexual encounter. Evidence shows that self-efficacy goes beyond predicting simple behavior and plays a central role in the prediction of initiation and maintenance of long-term healthy behavioral changes (Glanz et al., 2002). Health promotion campaigns designing interventions and/or curriculums on HPV preventative health behavior should create/enhance health educational experiences that augment collegeage women's efficacy to wear condoms.

\section{Study Limitations}

Findings of this study may not be generalized to populations outside of this University due to the small sample size of the priority population. This study utilized a self-administered survey. Only behavioral intentions were measured and there was no verification to see if the behaviors occurred. Furthermore, participants may have omitted certain questions and those that completed the whole questionnaire could have succumbed to social desirability or acquiescence. Since the questionnaire was handed out in a public setting participants may have had trouble dealing with issues of confidentiality and limited the truthfulness of their responses. 
Participant's might have had previous knowledge of HPV and cervical cancer because of conversations with partner(s), spouse, or family member that has had these HPV infection (or the men have/had HPV infection). It is also possible they could have learned about HPV and its links to cervical cancer in another setting and/or through mass media sources. Furthermore, HIV health promotion overshadows education of other STIs such as HPV (Yacobi et al., 1999) thus participants' may have performed well on the knowledge scale or shown intent to perform HPV preventative sexual behavior because of their background knowledge of HIV (in the questionnaire it was mentioned that HPV is a sexually transmitted infection). In addition, the subjects utilized in this study were university students, which generally tend to be more knowledgeable and informed than the overall population. Nonetheless, this study demonstrates that there is a need for greater HPV prevention education. College age women rate their understanding of HPV as poor and many are unaware that there is a vaccine available. Promoting self-efficacy is important as those participants with greater selfefficacy also demonstrated greater intent to have their partner use a condom.

\section{References}

Auvinen, E., Niemi, M., Malm, C., Zalliacus, R., Trontti, A., Fingerross, R. et al. (2006). High prevalence of HPV among female students in Finland. Scandanavia Journal of Infectious Diseases, 37, 873876.

Bandura, A. (1986). Social foundations of thought and action: A social cognitive theory. Englewood Cliffs, NJ: Prentice Hall.

Bosch, F., \& de Sanjose, S. (2003). Human papillomavirus and cervical cancer-burden and assessment of causality. Journal of the National Cancer Institute Monographs, 31, 3-13.

Burk, R., Ho, G., Beardsley, L., Lempa M., Peters, M., \& Bierman, R. (1996). Sexual behavior and partner characteristics are the predominant risk factors for genital Human Papillomavirus infection in young women. Journal of Infectious Diseases, 174, 679-689.

Franco, E., Schlecht, N., \& Saslow, D. (2003). The epidemiology of cervical cancer. The Cancer Journal. 9, 348-359.

Glanz, K., Lewis, F., \& Rimer, B. (2002). Health behavior and health education: theory, research and practice. San Francisco: Jossey-Bass.

Ingledue, K., Cottrell, R., \& Bernand, A. (2004). College women’s knowledge, perceptions, and preventive behaviors regarding Human Papillomavirus infection and cervical cancer. American Journal of Health Studies, 19(1), 28-34.

Koutsky, L. (1997). Epidemiology of genital Human Papillomavirus infection, American Journal of Medicine, 102, 3-8.

Lambert, E. (2001). College student's knowledge of Human Papillomavirus and effectiveness of a brief educational intervention. Journal of American Board Family Practice, 14, 178-183.

McPartland, T., Weaver, S., \& Koutsky L. (2005). Men's perceptions and knowledge of Human Papollomavirus (HPV) infection and cervical cancer. Journal of American College Health, 53, 225-230.

Petosa, R., \& Jackson, K. (1991) Using the health belief model to predict safer sex intentions among adolescents. Health Education Quorum, 18, 463-476.

Phillips, S. Johnson, M. Avis \& Whynes, DK. (2003) Human papillomavirus and the value of screening: young women's knowledge of cervical cancer. Health Education Research, 18, 318-328.

Pitts, M. \& Clarke, T. (2002). Human papillomavirus infections and risks of cervical cancer; what do women know? Health Education Research, 16, 706-714.

Ramirez, J., Ramos, D., Clayton, L., Kanowits, S., Mascicki, A. (1997). Genital human papillomavirus infection knowledge, perception of risk, and actual risk in a non-clinic population of young women. Journal of Women’s Health Gender Based Medicine, 6, 113-121. 
Schiffman M., \& Castle, P. (2003). Human papillomavirus: Epidemiology and public health. Archeology Pathology Laboratory Medicine, 127, 930-934.

Shin, H., Franceschi, S., Vaccarella, S., Roh, J., Ju, J., Oh, J. et al. (2004). Prevalence and determinants of genital infection with Papillomavirus, in female and male university students in Busan, South Korea. Journal of Infectious Diseases, 190, 468-476.

Vail-Smith, K., \& White, D. (1992). Risk level, knowledge, and preventive behavior for Human Papillomaviruses among sexually active college women. Journal of American College Health, 40, 227-230.

Winer, R., Lee, S., Hughes, J., Adam, D., Kiviat, N., \& Koutsky, L. (2003). Genital Human Papillomavirus infection: incidence and risk factors in a cohort of female university students. American Journal of Epidemiology, 157, 218-226.

Wulfert, E., \& Wan, C. (1993). Condom use: a self-efficacy model. Health Psychology, 12, 346-353.

Yacobi, E., Tennant, C., Ferrante, J., Pal., N., \& Roetzheim, R. (1999). University students’ knowledge and awareness of HPV, Preventive Medicine, 28, 535-541.

Zak-Place, J., \& Stern, M. (2004). Health belief factors and dispositional optimism as predictors of STD and HIV preventative behavior. Journal of American College Health, 52, 229-236.

\author{
Author Information \\ Ricardo Lopez, MPH \\ Research Associate \\ Department of Health Science \\ California State University, Fullerton \\ PO Box 6870 \\ Fullerton, CA 92834-6870 \\ Shari McMahan, Ph.D., CHES* \\ Professor and Chair \\ Department of Health Science \\ California State University, Fullerton \\ PO Box 6870 \\ Fullerton, CA 92834-6870 \\ Ph.: 714 278-7000 \\ Fax.: 714 278-5317 \\ E-Mail: smcmahan@fullerton.edu \\ * corresponding author
}




\section{Appendix A}

College-Age Women's Perception of HPV Based on Constructs of the Health Belief Model

\begin{tabular}{|c|c|}
\hline \multicolumn{1}{|c|}{ HBM Construct } & Percent \\
\hline Perceived Severity (n=172) & \\
\hline Yes & 83.1 \\
No & 16.9 \\
\hline Perceived Susceptibility (n=168) & \\
\hline Yes & 15.6 \\
No & 84.4 \\
\hline Perceived Benefits (n=172) & 60.5 \\
\hline Yes & 14.0 \\
No & 25.5 \\
Answered “Not Sexually Active” & \\
\hline Perceived Obstacles (n=172) & 65.7 \\
\hline Yes & 2.3 \\
No & 32.0 \\
Answered “Not Sexually Active” & \\
\hline Self-Efficacy (n=172) & 20.3 \\
\hline Yes & 47.1 \\
No & 32.6 \\
Answered “Not Sexually Active” & \\
\hline Intend to Wear Condoms (n=172) & 41.2 \\
\hline Yes & 26.2 \\
No & 32.6 \\
Answered “Not Sexually Active” & \\
\hline Intend to Reduce Future Sex Partners (n=172) & 57.0 \\
\hline Yes & 9.3 \\
No & 33.7 \\
Answered “Not Sexually Active” & \\
\hline
\end{tabular}




\section{Appendix B}

Unadjusted Odd Ratios of HBM Constructs with Intent to Wear Condoms and Intent to Reduce Number of Sex Partners

\begin{tabular}{|c|c|c|c|c|c|c|}
\hline \multirow[t]{2}{*}{ HBM Constructs } & \multicolumn{3}{|c|}{$\begin{array}{l}\text { Intent of Wearing Condoms } \\
\text { During the Next Sexual } \\
\text { Encounter to Prevent HPV } \\
\text { Infection }\end{array}$} & \multicolumn{3}{|c|}{$\begin{array}{c}\text { Intent of Reducing the } \\
\text { Number of Future Sex } \\
\text { Partners to Prevent HPV } \\
\text { Infection }\end{array}$} \\
\hline & $\mathbf{N}$ & OR & $(95 \% \mathrm{CI})$ & $\mathbf{N}$ & OR & (95 \% CI) \\
\hline \multicolumn{7}{|l|}{ Self-Efficacy } \\
\hline $\begin{array}{l}\text { Yes } \\
\text { No (Not Likely) }\end{array}$ & $\begin{array}{l}7 \\
62 \\
\end{array}$ & $\begin{array}{c}14.59 * \\
1.00\end{array}$ & $(5.44-39.14)$ & $\begin{array}{l}27 \\
70\end{array}$ & $\begin{array}{l}3.00 \\
1.00 \\
\end{array}$ & $(0.98-8.970$ \\
\hline \multicolumn{7}{|l|}{ Perceived Benefits } \\
\hline $\begin{array}{l}\text { Yes } \\
\text { No }\end{array}$ & $\begin{array}{l}56 \\
12 \\
\end{array}$ & $\begin{array}{l}1.17 \\
1.00 \\
\end{array}$ & $(0.45-3.05)$ & $\begin{array}{l}81 \\
16 \\
\end{array}$ & $\begin{array}{l}1.84 \\
1.00 \\
\end{array}$ & $(0.52-6.51)$ \\
\hline \multicolumn{7}{|l|}{ Perceived Severity } \\
\hline $\begin{array}{l}\text { Yes } \\
\text { No }\end{array}$ & $\begin{array}{l}55 \\
16 \\
\end{array}$ & $\begin{array}{l}.335 \\
1.00 \\
\end{array}$ & $(0.10-1.08)$ & $\begin{array}{l}82 \\
16 \\
\end{array}$ & $\begin{array}{l}1.71 \\
1.00 \\
\end{array}$ & $(0.49-6.0)$ \\
\hline \multicolumn{7}{|l|}{ Perceived Obstacles } \\
\hline $\begin{array}{l}\text { Yes } \\
\text { No }\end{array}$ & $\begin{array}{l}66 \\
1 * * \\
\end{array}$ & $\begin{array}{l}0.21 \\
1.00 \\
\end{array}$ & $(0.02-2.11)$ & $\begin{array}{l}93 \\
3 * *\end{array}$ & $\begin{array}{l}0.45 \\
1.00 \\
\end{array}$ & $(0.04-4.66)$ \\
\hline \multicolumn{7}{|c|}{ Perceived Susceptibility } \\
\hline \multirow{2}{*}{\multicolumn{7}{|c|}{$\begin{array}{c}\text { Yes } \\
\text { No } \\
\text { In Relationship }\end{array}$}} \\
\hline & & & & & & \\
\hline $\begin{array}{l}\text { Yes } \\
\text { No }\end{array}$ & $\begin{array}{l}50 \\
21 \\
\end{array}$ & $\begin{array}{c}3.36^{*} \\
1.00 \\
\end{array}$ & $(1.16-9.70)$ & $\begin{array}{l}80 \\
18 \\
\end{array}$ & $\begin{array}{c}0.23^{*} \\
1.00 \\
\end{array}$ & $(0.07-0.68)$ \\
\hline Heard of HPV & & & & & & \\
\hline $\begin{array}{l}\text { Yes } \\
\text { No }\end{array}$ & $\begin{array}{l}57 \\
14 \\
\end{array}$ & $\begin{array}{l}0.75 \\
1.00 \\
\end{array}$ & $(0.28-2.03)$ & $\begin{array}{l}78 \\
20 \\
\end{array}$ & $\begin{array}{l}1.80 \\
1.00 \\
\end{array}$ & $(0.38-8.54)$ \\
\hline Knowledge of HPV & & & & & & \\
\hline $\begin{array}{l}\text { Above } 50^{\text {th }} \\
\text { Below } 50^{\text {th }}\end{array}$ & $\begin{array}{l}44 \\
20 \\
\end{array}$ & $\begin{array}{l}0.91 \\
1.00 \\
\end{array}$ & $(0.40-2.09)$ & $\begin{array}{l}64 \\
26 \\
\end{array}$ & $\begin{array}{l}2.15 \\
1.00 \\
\end{array}$ & $(0.71-6.55)$ \\
\hline
\end{tabular}

* Significant at the $p<0.05$ level **Expected count less than 5 